\title{
X-ray Investigation of Gold-Cadmium Alloys Rich in Gold
}

\author{
ANDERS BYSTRÖM and KARLERIK ALMIN \\ Institute of General and Inorganic Chemistry, University of Stockholm, Sweden
}

T his X-ray study of gold-rich gold-cadmium alloys was carried out because of discrepancies in the results of the investigations of this system by Ölander, ${ }^{1}$ Köster and Schneider, ${ }^{2}$ Owen and Roberts, ${ }^{3}$ and Owen and Rees. ${ }^{4}$ These previous investigations of the system differ in the methods applied. Ölander investigated the system by measuring the potential of the cell $\mathrm{Cd}_{\text {liq. }}$. electrolyte $\mid(\mathrm{Cd}, \mathrm{Au})_{\text {solid }}$ and determined its temperature coefficient for different compositions of the alloy electrode. Owen and co-workers, on the other hand, made an $X$-ray analysis of the system, and Köster and Schneider combined the $\mathrm{X}$-ray analysis with measurements of the modulus of elasticity.

As Ölander states in his paper, there was some difficulty in measuring electrodes of $\alpha$-alloys. The diffusion in these alloys was rather small and thus the surface composition of the electrodes could easily differ from the gross composition. To avoid this, Ölander measured the $\alpha$-alloys not against liquid cadmium but against electrodes of $\alpha+\beta$-alloys, thus lowering the cadmium gas pressure considerably. In fig. 1, Ölander's potential measurements for the

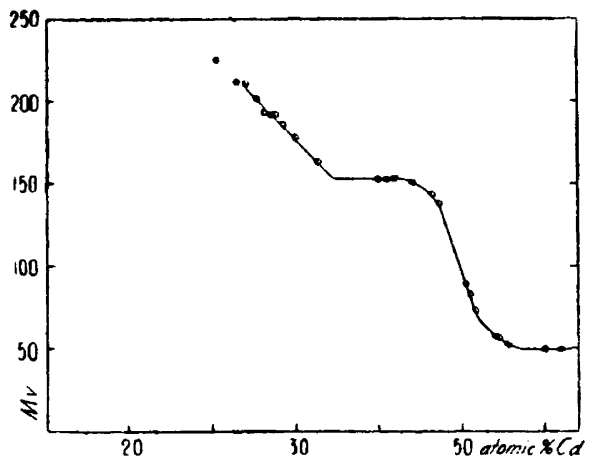

Fig. 1. Potential of the cell $\mathrm{Cd} / \mathrm{KCl}, \mathrm{LiCl}$, $\mathrm{CdCl}_{2} /(\mathrm{Cd}, \mathrm{Au})$ at $427^{\circ} \mathrm{C}$ according to ölander. 
gold-rich gold-cadmium alloys are reproduced. As will be seen from the figure, there may possibly be a narrow two-phase region at about 23 atomic \% Cd. This was later established by Owen and Roberts. However, Owen and Roberts not only divided the $\alpha$-region of Ölander in $\alpha, \alpha+\alpha_{2}$, and $\alpha_{2}$ regions, but also found a new phase at about 45 atomic $\% \mathrm{Cd}$, called $\alpha_{3}$, and the existence of this phase is certainly not indicated by the potential measurements of Ölander.

\section{EXPERIMENTAL}

The alloys were made from $99.98 \%$ gold from the Boliden Mining Company and cadmium pro anal. from Kahlbaum with a purity of at least $99.9 \%$. The following cell dimensions were found for the two metals: $\mathrm{Au} a=4.068$ $\pm .002 \mathrm{kX}, \mathrm{Cd} a=2.973 \pm .002 \mathrm{kX}, c=5.604 \pm .003 \mathrm{kX}$. Within the estimated errors these values agree with the precision determinations by Jette and Foote for $\mathrm{Au}(a=4.0704 \mathrm{kX})$ and for $\mathrm{Cd}(a=2.9731 \mathrm{kX}, c=$ $5.6069 \mathrm{kX}) .^{5}$

Two types of X-ray cameras were employed. Focussing cameras were used for the quenched alloys, and a high-temperature camera with $72 \mathrm{~mm}$ diam. was used when the $\beta$-alloys were investigated. With the focussing cameras the precision in the determination of the cell dimensions is about $0.05 \%$. The temperature measurements were made with Fe-constantan and Pt-PtRh thermo-couples, which were checked during the course of work.

The alloys were prepared from weighed quantities of the metals - these having been sealed in evacuated silica tubes and melted. The ingots were then lump-annealed at $500-600^{\circ} \mathrm{C}$ and rapidly air-cooled. Afterwards the ingots were weighed and the loss in weight was always sufficiently small to make it possible to conclude that the composition of the ingots was within 0.1 atomic $\%$ of that intended. This was confirmed by chemical analyses of some samples chosen at random. For the analyses, the samples were dissolved in a mixture of hydrochloric and nitric acid. The solution was evaporated to dryness, hydrochloric acid was added and evaporated twice. Then the mixture of chlorides was dissolved in dilute hydrochloric acid and the gold reduced with $\mathrm{SO}_{2}$. The gold was taken on filter paper, ignited in a porcelain crucible and weighed. Sulphuric acid was added to the filtrate, and the solution was evaporated until sulphuric acid fumes appeared. The final evaporation was made in a platinum crucible, in which the solid residue of cadmium sulphate was weighed after being heated to a constant weight at about $550^{\circ} \mathrm{C}$.

For the investigation of quenched alloys, samples were prepared by taking filings from the ingots. The rilings were placed in small thin-walled silica tubes, which were evacuated and put to anneal at the intended temperature. The temperature of the furnace was controlled by a regulator (Hartmann and Brauns "Kleinregler") and was constant within $5^{\circ} \mathrm{C}$.

For the high temperature camera, wires were cast in the following way: The sample was placed in a small bulb of silica. To the mouth of the bulb, a capillary tube was attached, this being bent to a U-form with the shank on the bulb-side very short. The 


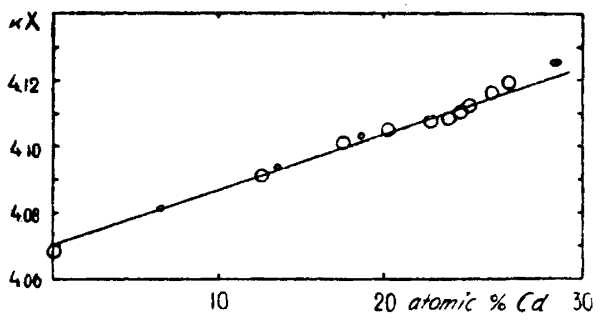

Fig. 2. The parameter-composition curve for the a-phase. The small circles show the measurements of Owen and Roberts.

bulb was evacuated through the capillary tube and filled with hydrogen. Then the sample was heated above the melting point. By the pressure of the hydrogen in the bulb, and by the application of a small suction to the tube, the molten alloy was forced into the capillary tube which after cooling was crushed. In the high-temperature camera the wires were heated by a little electrical furnace. The camera was filled with hydrogen during the exposure.

\section{THE $\alpha \cdot, \alpha^{\prime} \cdot$, AND $\alpha_{2}$-PHASES}

In fig. 2 the parameter-composition curve at room temperature for the cubic $\alpha$-phase is shown. As will be seen, the cell dimensions determined by Owen and Roberts, and those determined by ourselves, fit rather well on the same curve. The existence of a hexagonal $\alpha_{2}$-phase was clearly demonstrated by the powder photographs. For the position of the boundary $\alpha-\left(\alpha+\alpha_{2}\right)$ our results agree well with those of Owen and Roberts. The boundaries of the narrow regions $\alpha+\alpha^{\prime}, \alpha^{\prime}$, and $\alpha^{\prime}+\alpha_{2}$, are rather difficult to determine. In a series of alloys with $20.2,22.8,24.6,25.3$, and 25.9 atomic $\% \mathrm{Cd}$ annealed at $350^{\circ} \mathrm{C}$, the first one only gave reflections belonging to the $\alpha$-phase, and the following two only gave reflections belonging to the tetragonal $\alpha^{\prime}$-phase, whereas the last two showed reflections belanging to both the $\alpha$ and the $\alpha_{2}$ phase. The lattice constants of the $\alpha^{\prime}$-phase were:

$\begin{array}{ccccc}\text { Atomic } \% \mathrm{Cd} & a \text { in } \mathrm{kX} & c \text { in } \mathrm{kX} & \frac{c}{a} & V \text { in } \mathrm{kX}^{3} \\ 22.8 & 4.099 & 4.130 & 1.008 & 69.39 \\ 24.6 & 4.103 & 4.124 & 1.005 & 69.43\end{array}$

The tetragonal deformation is somewhat larger than that found by Owen and Roberts. Judging from these samples the $\alpha+\alpha^{\prime}$ region is a little narrower and the $\alpha^{\prime}$-region a little wider than that shown by the phase diagram of Owen and Roberts. It is evident from these figures that the deformation of the tetragonal cell decreases with increasing cadmium percentage. In the two-phase region $\alpha^{\prime}+\alpha_{2}$, the cell seemed to be cubic but the photographs of these alloys were diffuse and a faint tetragonal deformation may exist without having been observed. 
In photographs of slowly cooled alloys of the composition $\mathrm{Au}_{3} \mathrm{Cd}$, Köster and Schneider observed super-lattice lines. On the other hand, Owen and Roberts stated that no super-lattice reflections were present in the powder photographs of $\alpha^{\prime}$-alloys. According to them, the structure of these alloys was face-centered tetragonal. Saldau, ${ }^{6}$ however, found a high electrical conductivity for the $\alpha^{\prime}$-phase and this should indicate an ordered distribution of the atoms.

Contrary to Owen and Roberts, we found in the photographs of the $\alpha^{\prime}$-phase super-lattice lines showing an ordered distribution of the cadmium and gold atoms. The structure can be described as follows:

$$
\begin{array}{ll}
\text { Space group } D_{4 h}^{\mathrm{I}}-\mathrm{P} 4 / \mathrm{mmm} \quad & 1 \mathrm{Cd} \text { in 1(a): } 000 \\
& 1 \mathrm{Au} \text { in } 1(\mathrm{c}): \frac{1}{2} \frac{1}{2} 0 \\
& 2 \mathrm{Au} \text { in 2(e): } 0 \frac{1}{2} \frac{1}{2}, \frac{1}{2} \mathrm{O} \frac{1}{2}
\end{array}
$$

As is seen from table 1, the agreement between observed and calculated intensities is quite satisfactory.

\begin{tabular}{|c|c|c|c|c|c|c|c|c|c|}
\hline$h k l$ & $\begin{array}{c}\sin ^{2} \Theta \\
\text { obs. }\end{array}$ & $\begin{array}{l}\sin ^{2} \Theta \\
\text { cale }\end{array}$ & $\begin{array}{c}I \\
\text { obs. }\end{array}$ & $\begin{array}{c}I \\
\text { calc. }\end{array}$ & $h k l$ & $\begin{array}{c}\sin ^{2} \Theta \\
\text { obs. }\end{array}$ & $\begin{array}{c}\sin ^{2} \Theta \\
\text { calc. }\end{array}$ & $\begin{array}{c}I \\
\text { obs. }\end{array}$ & $\begin{array}{c}I \\
\text { calc. }\end{array}$ \\
\hline 101$)$ & 01003 & $\{0.1103$ & & $\int 1.0$ & 300 & - & .5004 & - & 0.1 \\
\hline 110$\}$ & 0.1093 & .1111 & v.w. & 0.5 & 103 & - & .5483 & - & 0.1 \\
\hline 111 & .1649 & .1659 & v.st. & 38 & $301)$ & & .5547 & & $\int 0.1$ \\
\hline 002 & .2184 & .2190 & m. & 6.7 & $310\}$ & .5547 & .5556 & v.w.- & $\{0.1$ \\
\hline 200 & .2218 & .2222 & st. & 13 & 113 & .6040 & .6040 & m. & 7.1 \\
\hline 102 & .2750 & .2746 & v.w. & 0.3 & 311 & .6104 & .6104 & st. & 14 \\
\hline 201) & & .2772 & & (0.3 & 222 & .6645 & .6634 & m. & 7.3 \\
\hline 210$\}$ & .2794 & .2778 & v.w. + & $\{0.3$ & 203 & - & .7151 & - & 0.1 \\
\hline 112) & & .3301 & & $\int 0.2$ & 302 & - & .7191 & - & 0.1 \\
\hline 211\} & .3319 & .3326 & v.w. + & $\{0.4$ & 320 & - & .7223 & - & 0.1 \\
\hline 202$\}$ & & .4412 & & $\{9.3$ & 213 & - & .7716 & $\ldots$ & 0.2 \\
\hline 220$\}$ & .4422 & .4444 & st.br. & $\{4.6$ & $312\}$ & & .7746 & & 0.2 \\
\hline 003 & 一 & .4928 & - & 0.0 & $321\}$ & .7764 & .7770 & v.w. & $\{0.2$ \\
\hline 212 & - & .4968 & - & 0.3 & 004 & .8771 & .8762 & w. & 2.6 \\
\hline 221) & 4970 & .4992 & & $\{0.1$ & $400^{\circ}$ & .8898 & .8888 & m. & 5.5 \\
\hline$\beta$ 113\} & .4970 & & w. & 1.4 & & & & & \\
\hline
\end{tabular}

Table 1. Powder photographs of $\alpha^{\prime}$-alloy with 22.8 atomic $\% \mathrm{Cd}$. Quenched from $350^{\circ} \mathrm{C}$.

$F e-\underline{K}$ radiation. $\beta$-reflections are omitted when not coinciding with a-reflections.

However, these super-lattice reflections were observed not only in the photographs of the tetragonal $\alpha^{\prime}$-phase but also in those of the cubic $\alpha$-phase of compositions in the vicinity of the formula $\mathrm{Au}_{3} \mathrm{Cd}$. This modification we 
call $\alpha^{\prime \prime}$. As was expected, the intensity of the super-lattice reflections decreased with increasing annealing temperature but they could still be observed, though very weak, in the photographs of samples annealed at $550^{\circ} \mathrm{C}$.

The parameters of the $\alpha_{2}$-lattice for different compositions are collected in the table below:

\begin{tabular}{clcc} 
Atomic \% Cd & \multicolumn{1}{c}{$a$ in $\mathrm{kX}$} & $c$ in $\mathrm{kX}$ & $V$ in $\mathrm{kX}^{3}$ \\
25.7 & $2.902 \pm .002$ & $4.774 \pm .003$ & 34.83 \\
27.5 & 2.904 & 4.777 & 34.89 \\
28.2 & 2.904 & 4.779 & 34.91 \\
30.0 & 2.907 & 4.790 & 35.07 \\
33.3 & 2.909 & 4.802 & 35.21
\end{tabular}

The lattice dimensions now given differ rather considerably from those obtained by Owen and Roberts. In spite of this fact, our determinations of the boundaries of the $\alpha_{2}$-region agree fairly well with those of Owen and Roberts. We calculated the $\alpha_{2}-\left(\alpha_{2}+\beta\right)$ boundary to be at $33.3\left(200^{\circ} \mathrm{C}\right)$, $34.8\left(400^{\circ} \mathrm{C}\right)$, and $35.8\left(550^{\circ} \mathrm{C}\right)$ atomic $\% \mathrm{Cd}$, agreeing very well with the values 33.2 (extrapolated), 35.0 and 35.5 obtained by Owen and Roberts. The other boundary of the $\alpha_{2}$-region is more difficult to determine because of the diffuse reflections of the photographs, but the only deviation which perhaps slightly exceeds the accuracy of the measurements is at $550^{\circ} \mathrm{C}$, where we found the boundary to be at 28.6 atomic \% Cd instead of 29.1.

According to Owen and Roberts the structure of the $\alpha_{2}$-phase is closepacked hexagonal. In table 2 the reflections of a sample of the composition $\mathrm{Au}_{2} \mathrm{Cd}$ are listed. The intensities are calculated for a random structure, i.e. $\frac{2}{3} \mathrm{Cd}$ and $\frac{4}{3} \mathrm{Au}$ in the position 2 (c): $\frac{1}{3} \frac{2}{3} \frac{1}{4} ; \frac{2}{3} \frac{1}{3} \frac{3}{4}$ of the space-group $\mathrm{D}_{6 \mathrm{~h}}^{4}-\mathrm{C} 6 / \mathrm{mmc}$. The agreement between observed and calculated intensities is good, the observed high intensity of the reflections 002 and 004 certainly being due to a preferred orientation of the crystallites. However, the structure

Table 2. Powder photographs of $\alpha_{2}$-alloy with 33.3 atomic $\% \mathrm{Cd}$, quenched from $450^{\circ} \mathrm{C}$. Fe-K radiation.

\begin{tabular}{lllll|llllr}
$h k l$ & $\begin{array}{l}\sin ^{2} \Theta \\
\text { obs. }\end{array}$ & $\begin{array}{l}\sin ^{2} \Theta \\
\text { calc. }\end{array}$ & $\begin{array}{c}I \\
\text { obs. }\end{array}$ & $\begin{array}{c}I \\
\text { calc. }\end{array}$ & $h k l$ & $\begin{array}{c}\sin ^{2} \Theta \\
\text { obs. }\end{array}$ & $\begin{array}{l}\sin ^{2} \Theta \\
\text { calc. }\end{array}$ & $\begin{array}{c}I \\
\text { obs. }\end{array}$ & $\begin{array}{r}I \\
\text { calc. }\end{array}$ \\
100 & 0.1457 & 0.1472 & m. & 21 & 112 & .6027 & .6035 & st. & 25 \\
002 & .1607 & .1620 & st. & 25 & 201 & .6284 & .6293 & m. & 18 \\
101 & .1863 & .1877 & v.st. & 88 & 004 & .6480 & .6478 & m. & 4 \\
102 & .3084 & .3092 & st. & 14 & 202 & .7510 & .7508 & w. & 7 \\
110 & .4408 & .4416 & m. & 16 & 104 & .7947 & .7950 & w. & 7 \\
103 & .5113 & .5116 & st. & 20 & 203 & .9532 & .9532 & st. & 43 \\
200 & .5880 & .5888 & v.w. & 3 & & & & &
\end{tabular}


Table 3. Comparison between observed intensities in powder photographs of $\alpha_{2}$-alloys of different compositions quenched from $450^{\circ} \mathrm{C}$.

\begin{tabular}{|c|c|c|c|c|c|c|c|}
\hline & 25.7 atomic & 29.5 atomic & 33.3 atomic & & 25.7 atomic & 29.5 atomic & 33.3 atomic \\
\hline$h k l$ & $\% \mathbf{C d}$ & $\% \mathrm{Cd}$ & $\% \mathrm{Cd}$ & $h k l$ & $\% \mathbf{C d}$ & $\% \mathrm{Cd}$ & $\% \mathrm{Cd}$ \\
\hline 100 & w.d. & w.d. & m. & 103 & $\dot{v} . w . d$. & w.d. & st. \\
\hline 002 & st. & st. & st. & 200 & - & v.w.d. & w. \\
\hline 101 & v.w.d. & w.d. & v.st. & 112 & v.st. & st. & st. \\
\hline 102 & - & v.w.d. & st. & 201 & - & w.d. & m. \\
\hline 110 & m. & m. & m. & 004 & m. & m. & m. \\
\hline
\end{tabular}

of this phase is not so simple at lower cadmium percentages. In table 3 the intensities of some reflections are compared at different compositions of the phase. It is obvious that the atomic arrangement of these three preparations must differ considerably.

As will be seen from table 3 , there are in the photographs of $\alpha_{2}$-alloys with 25.7 and 29.5 atomic \% $\mathrm{Cd}$ some reflections which are weakened and diffuse while others remain sharp and apparently with about the same intensity as in the photographs of the alloy with 33.3 atomic \% Cd. The broadening of these reflections is considerable: in the photographs of a preparation with 28.2 atomic $\% \mathrm{Cd}$ (quenched from $350^{\circ} \mathrm{C}$ ) the diffuse reflections $(100,101$, $102,103,200,201)$ seem to be $4-6$ times broader than the sharp ones (002, $110,112,004,114)$.

Broadened reflections in photographs often indicate that the crystallites of the preparation are very small. The sharpness of 002 and 004 shows clearly that in the direction of the $c$-axis the crystallites are at least $10^{-4} \mathrm{~cm}$. Thus the crystallites should be thin in the $a$-direction, but this is contradicted by the sharpness of 110 and 112, which in this case must be broadened as is for instance 103. From these facts the conclusion must be drawn that the broadening of the reflections must depend on some special feature in the arrangement of atoms.

Now the structure of these alloys cannot differ much from a hexagonal close-packed one, as all reflections to be expected from that structure are present in the photographs of the alloy with 29.5 atomic $\% \mathrm{Cd}$ and only three of them are missing in those of the alloy with 25.7 atomic \% $\mathrm{Cd}$. Of these missing reflections, 200 has the lowest calculated intensity of the listed ones (see table 2). 102 would be expected to appear near the inner end of one of the three photographs which were taken with our focussing cameras to cover the whole range. At this end the general blackening is very marked. 201 would be expected to appear near the other end of the photograph where the special intensity factors of the focussing cameras considerably weaken the intensity of the reflections. 
In the photographs of hexagonal cobalt, Edwards and Lipson? have observed a similar mixture of sharp and diffuse reflections. This is explained by them as being due to occasional faults in the structure, making a sequence $\mathrm{ABABAB} \ldots$ change over to $\mathrm{BCBCBC} \ldots$ and so on $(\mathrm{A}, \mathrm{B}$, and $\mathrm{C}$ representing three layers of close-packing with $x, y$-coordinates $00, \frac{1}{3} \frac{2}{3}$, and $\frac{2}{3} \frac{1}{3}$ for the atoms respectively). Obviously the reflections 001 are not affected by these faults as the 001 spacing is still perfect. For the other reflections Edwards and Lipson have shown that those with $\frac{1}{3}(h-k)=$ an integer and 1 even have normal intensities, whereas those with $\frac{1}{3}(h-k)=$ an integer $\pm \frac{1}{3}$ would give weakened and (if the faults are repeated at irregular intervals) blurred reflections. Thus, just as we observed them to appear, 002, 110,112 , and 004 should be sharp reflections and the other more or less diffuse.

\section{THE $\beta$ - AND $\beta^{\prime}$-PHASES}

In addition to the electrochemical investigation of the system $\mathrm{Au}-\mathrm{Cd}$, Ölander carried out a structure determination for the $\beta$ and $\beta^{\prime}$-phases. ${ }^{8}$ The report of this latter investigation does not seem to have been observed by Owen and Rees. For the $\beta$-phase Ölander found the structure to be of the CsCl-type with a cube edge at about $400^{\circ} \mathrm{C}$ of $3.34 \mathrm{kX}$ for an alloy with 47.5 atomic $\% \mathrm{Cd}$. The $\beta^{\prime}$-phase was shown to be orthorhombic and had by the same composition the dimensions at room temperature $a=3.144 \mathrm{kX}, b=$ $4.851 \mathrm{kX}$, and $c=4.755 \mathrm{kX}$. The space group is $\mathrm{D}^{2}$. The two cadmium atoms are situated in 000 and $0 \frac{5}{8} \frac{1}{2}$ and the two gold atoms in $\frac{1}{2} \frac{1}{2} 0$ and $\frac{1}{2} \frac{1}{8} \frac{1}{2}$. This atomic arrangement can be looked upon as a deformed CsCl-structure. Ölander found a transition point at $267^{\circ} \mathrm{C}$ and believed this transition to be $\beta^{\prime} \rightarrow \beta$. The existence of an orthorhombic modification of AuCd was later denied by Köster and Schneider. They thought that the low-temperature modification was tetragonal with $a=5.074 \mathrm{kX}$ and $c=4.487 \mathrm{kX}$.

In the gold-rich part of the $\beta$-region Owen and Rees believed that they had found a new phase which they denoted $\alpha_{3}$. The reflections in the powder photographs were said to fit on a rhombohedral hexagonal chart in a position with $\frac{c}{a}=2.301$. The hexagonal cell was said to have $a=5.473 \mathrm{kX}$ and $c=12.593$ $\mathrm{kX}$. They divided the rest of Ölanders $\beta$-region into a two-phase region $\alpha_{3}+\beta$ and a single phase region, $\beta$, without the transition $\beta^{\prime} \rightarrow \beta$. As is seen from the cell dimensions of this $\alpha_{3}$-phase its $c$-axis is 4 times the $a$-axis of Ölanders $\beta^{\prime}$ phase. There seems, however, to be no relation between the $a$-axis of $\alpha_{3}$ and the $b$ - and $c$-axis of $\beta^{\prime}$. (The $a$-axis of $\alpha_{3}$ is $\sqrt{3}$ times the $a$-axis of $\beta^{\prime}$ ):

In order to settle the question concerning the existing phases in this part of the phase diagram, a series of alloys was prepared with compositions ran- 
ging from 40.2 to 54.2 atomic $\% \mathrm{Cd}$. Filings of these alloys were then annealed at $200^{\circ} \mathrm{C}$ (14 days), $400^{\circ} \mathrm{C} \mathrm{(3} \mathrm{days),} \mathrm{and} 550^{\circ} \mathrm{C}$ (26 hours), and then quenched. The phases that could be identified in the powder photographs of these preparations are listed in the table below.

$\begin{array}{clll}\text { Atomic } \% \mathrm{Cd} & 200^{\circ} \mathrm{C} & 400^{\circ} \mathrm{C} & 550^{\circ} \mathrm{C} \\ 40.2 & a_{2}+\beta^{\prime} & \alpha_{2}+\beta^{\prime}+\mathrm{x}_{1} & \alpha_{2}+\beta^{\prime} \\ 43.0 & \alpha_{2}+\beta^{\prime} & \alpha_{2}+\beta^{\prime}+\mathrm{x}_{1} & \alpha_{2}+\beta^{\prime} \\ 46.3 & \beta^{\prime}+\alpha_{2} & \beta^{\prime}+\mathrm{x}_{1} & \beta^{\prime} \\ 48.1 & \beta+\beta^{\prime}+\mathrm{x}_{2} & \beta+\beta^{\prime}+\mathrm{x}_{2} & \beta+\beta^{\prime}+\mathrm{x}_{2} \\ 50.1 & \beta+\mathrm{x}_{2} & \beta+\mathrm{x}_{2} & \beta+\mathrm{x}_{2} \\ 54.2 & \beta+\mathrm{x}_{2} & \beta+\mathrm{x}_{2} & \beta+\mathrm{x}_{2}\end{array}$

The photographs of most of the preparations which are listed above show some reflections which we have not been able to identify. These extra reflections seem to belong to two different patterns. One of them appears in the photographs of the $\beta^{\prime}$-phase ( $x_{1}$ in the table above). In this case there are only a few unidentified reflections (table 4 ) while in the other case ( $x_{2}$ in the table) the number of unidentified reflections is rather large (table 5). The

Table 4. Powder photographs of Au-Cd alloy with 46.3 atomic \% Cd. Quenched from $400^{\circ} \mathrm{C}$. Fe-K radiation.

\begin{tabular}{|c|c|c|c|c|c|c|c|c|c|c|c|}
\hline$h k l$ & $\mathbf{R}$ & $\begin{array}{c}\sin ^{2} \Theta \\
\text { obs. }\end{array}$ & $\begin{array}{r}\sin ^{2} \Theta \\
\text { calc. }\end{array}$ & $\begin{array}{c}I \\
\text { obs. }\end{array}$ & Phase & $h k l$ & $\mathbf{R}$ & $\begin{array}{c}\sin ^{2} \Theta \\
\text { obs. }\end{array}$ & $\begin{array}{c}\sin ^{2} \Theta \\
\text { calc. }\end{array}$ & $\begin{array}{c}I \\
\text { obs. }\end{array}$ & Phase \\
\hline 100 & $\alpha$ & 0.0946 & 0.0958 & v.w. & $\beta^{\prime}$ & 022 & $a$ & .3223 & .3227 & m. + & $\beta^{\prime}$ \\
\hline$?$ & & .1102 & & v.w. & $x_{1}$ & 130 & $\beta$ & .3705 & & w. & $\beta^{\prime}$ \\
\hline 020 & $\beta$ & .1286 & & w. & $\beta^{\prime}$ & 200 & $a$ & .3826 & .3831 & $\mathrm{~m}$. & $\beta^{\prime}$ \\
\hline 002 & $\beta$ & .1344 & & m. & $\beta^{\prime}$ & 131 & $\beta$ & .4034 & & v.w. & $\beta^{\prime}$ \\
\hline 111 & $\beta$ & .1442 & & m. & $\beta^{\prime}$ & $?$ & & .4098 & & v.w. & $x_{1}$ \\
\hline 020 & $\alpha$ & .1566 & .1574 & m. & $\beta^{\prime}$ & 113 & $\beta$ & .4164 & & m. & $\beta^{\prime}$ \\
\hline 002 & $a$ & .1642 & .1653 & m. + & $\beta^{\prime}$ & 220 & $\beta$ & .4438 & & v.w. & $\beta^{\prime}$ \\
\hline$?$ & & .1711 & & w. & $x_{1}$ & 130 & $\alpha$ & .4493 & .4499 & m. + & $\beta^{\prime}$ \\
\hline 111 & $a$ & .1756 & .1764 & st. & $\beta^{\prime}$ & 211 & $\alpha$ & .4640 & .4637 & v.w. & $\beta^{\prime}$ \\
\hline$?$ & & .1795 & & w. & $x_{1}$ & 221 & $\beta$ & .4784 & & v.w. & $\beta^{\prime}$ \\
\hline 021 & $\alpha$ & .1979 & .1987 & m. & $\beta^{\prime}$ & 131 & $\alpha$ & .4913 & .4913 & m. & $\beta^{\prime}$ \\
\hline 102 & $\beta$ & .2141 & & v.w. & $\beta^{\prime}$ & 113 & $a$ & .5063 & .5070 & st. & $\beta^{\prime}$ \\
\hline$?$ & & .2280 & & v.w. & $x_{1}$ & $?$ & & .5193 & & v.w. & $x_{1}$ \\
\hline 112 & $\beta$ & .2469 & & v.w. & $\beta^{\prime}$ & 023 & $a$ & .5287 & .5293 & v.w. + & $\beta^{\prime}$ \\
\hline 120 & $a$ & .2530 & .2532 & v.w. + & $\beta^{\prime}$ & 220 & $\alpha$ & .5411 & .5405 & m. & $\beta^{\prime}$ \\
\hline 102 & $a$ & .2595 & .2611 & w. & $\beta^{\prime}$ & 202 & $\alpha$ & .5482 & .5484 & m. & $\boldsymbol{\beta}^{\prime}$ \\
\hline 022 & $\beta$ & .2648 & & w. & $\beta^{\prime}$ & 221 & $\alpha$ & .5812 & .5818 & m. & $\beta^{\prime}$ \\
\hline 121 & $\alpha$ & .2937 & .2945 & v.w. & $\beta^{\prime}$ & 132 & $\alpha$ & .6157 & .6152 & m. & $\beta^{\prime}$ \\
\hline 112 & $a$ & .2996 & .3004 & w. & $\beta^{\prime}$ & 004 & $a$ & .6605 & .6612 & m. & $\beta^{\prime}$ \\
\hline$?$ & & .3056 & & v.w. & $x_{1}$ & 041 & $\alpha$ & .6723 & .6710 & m. & $\beta^{\prime}$ \\
\hline 200 & $\beta$ & .3138 & & v.w. & $\boldsymbol{\beta}^{\prime}$ & 222 & $a$ & .7050 & .7058 & m. & $\boldsymbol{\beta}^{\prime}$ \\
\hline
\end{tabular}


Table 5. Powder photographs of Au-Cd alloy with 50.1 atomic $\% \mathrm{Cd}$, quenched from $400^{\circ} \mathrm{C}$. Fe-K radiation.

\begin{tabular}{|c|c|c|c|c|c|c|c|c|c|c|c|}
\hline$h k l$ & $\mathbf{R}$ & $\begin{array}{c}\sin ^{2} \Theta \\
\text { obs. }\end{array}$ & $\frac{\sin ^{2} \Theta \text { obs. }}{\Sigma h^{2}}$ & $\begin{array}{c}I \\
\text { obs. }\end{array}$ & Phase & $h k l$ & $\mathbf{R}$ & $\begin{array}{c}\sin ^{2} \Theta \\
\text { obs. }\end{array}$ & $\frac{\sin ^{2} \Theta \text { obs. }}{\Sigma h^{2}}$ & $\begin{array}{c}I \\
\text { obs. }\end{array}$ & Phase \\
\hline 100 & $\begin{array}{l}a \\
a \\
a\end{array}$ & $\begin{array}{r}0.0841 \\
.1300 \\
.1330\end{array}$ & 0.0841 & $\begin{array}{l}\text { m. } \\
\text { w. } \\
\text { w. }\end{array}$ & $\begin{array}{l}\beta \\
\mathbf{x}_{2} \\
\mathbf{x}_{2}\end{array}$ & & $\begin{array}{l}\alpha \\
\alpha \\
\alpha\end{array}$ & $\begin{array}{l}.4652 \\
.4737 \\
.5037\end{array}$ & & $\begin{array}{l}\text { w. } \\
\text { m. } \\
\text { w. }\end{array}$ & $\begin{array}{l}x_{2} \\
x_{2} \\
x_{2}\end{array}$ \\
\hline & $\beta$ & .1382 & & $\mathrm{~m}$. & $x_{2}$ & 211 & $\alpha$ & .5131 & .0855 & st. & $\beta$ \\
\hline 110 & $\begin{array}{l}\beta \\
\beta\end{array}$ & $\begin{array}{l}.1408 \\
.1540\end{array}$ & .0704 & $\begin{array}{l}\text { m. } \\
\text { w. }\end{array}$ & $\begin{array}{l}\beta \\
\mathrm{x}_{2}\end{array}$ & & $\begin{array}{l}a \\
\beta\end{array}$ & $\begin{array}{l}, 5334 \\
.5558\end{array}$ & & $\begin{array}{l}\text { w. } \\
\text { v.w. }\end{array}$ & $\begin{array}{l}x_{2} \\
x_{2}\end{array}$ \\
\hline & $a$ & .1600 & & v.w. & $x_{2}$ & 220 & $\beta$ & .5646 & .0706 & v.w. & $\beta$ \\
\hline 110 & $\begin{array}{l}a \\
a\end{array}$ & $\begin{array}{l}.1680 \\
.1710\end{array}$ & .0855 & $\begin{array}{l}\text { v.st. } \\
\text { v.st. }\end{array}$ & $\begin{array}{l}\mathrm{x}_{2} \\
\beta\end{array}$ & & $\begin{array}{l}\alpha \\
a\end{array}$ & $\begin{array}{l}.5712 \\
.5793\end{array}$ & & $\begin{array}{l}\text { v.w. } \\
\text { w. }\end{array}$ & $\begin{array}{l}x_{2} \\
x_{2}\end{array}$ \\
\hline & $a$ & .1744 & & v.w. & $x_{2}$ & & $\alpha$ & .5875 & & $\mathrm{~m}$. & $x_{2}$ \\
\hline & $\alpha$ & .1779 & & v.w. & $x_{2}$ & & $\alpha$ & .6166 & & $\mathbf{m}$. & $x_{2}$ \\
\hline & $\alpha$ & .1870 & & m. + & $x_{2}$ & & $\alpha$ & .6456 & & v.w. & $x_{2}$ \\
\hline & $\beta$ & .2009 & & w. - & $x_{2}$ & & $a$ & .6749 & & w. & $x_{2}$ \\
\hline & $a$ & .2444 & & m. & $x_{2}$ & 220 & $a$ & .6866 & .0858 & m. & $\beta$ \\
\hline 111 & $\alpha$ & .2563 & .0854 & w. & $\beta$ & & $\alpha$ & .6943 & & w. & $x_{2}$ \\
\hline 200 & $\begin{array}{l}\beta \\
\alpha\end{array}$ & $\begin{array}{l}.2789 \\
.3081\end{array}$ & .0697 & $\begin{array}{l}\text { w. } \\
\text { v.w. }\end{array}$ & $\begin{array}{l}\beta \\
\mathrm{x}_{2}\end{array}$ & 310 & $\begin{array}{l}\beta \\
\mathrm{a}\end{array}$ & $\begin{array}{l}.7055 \\
.7523\end{array}$ & .0706 & $\begin{array}{l}\text { w. } \\
\text { v.w. }\end{array}$ & $\beta$ \\
\hline 200 & $\begin{array}{l}\alpha \\
\alpha\end{array}$ & $\begin{array}{l}.3399 \\
.3609\end{array}$ & .0850 & $\begin{array}{l}\text { st. } \\
\text { v.w. }\end{array}$ & $\begin{array}{l}\beta \\
\mathrm{x}_{2}\end{array}$ & $\left.\begin{array}{l}300 \\
221\end{array}\right\}$ & & .7717 & .0857 & v.v.w. & $\beta$ \\
\hline & $\beta$ & .3848 & & v.w. & $x_{2}$ & & & .7830 & & v.v.w. & $x_{2}$ \\
\hline & $\beta$ & .3897 & & v.w. & $x_{2}$ & & & .7917 & & v.v.w. & $x_{2}$ \\
\hline & $\beta$ & $\begin{array}{l}.4142 \\
.4215\end{array}$ & & $\begin{array}{l}\text { v.w. } \\
\text { m. }\end{array}$ & $\begin{array}{l}\mathrm{x}_{2} \\
\beta\end{array}$ & & & .8083 & & v.v.w. & $x_{2}$ \\
\hline 210 & $\begin{array}{l}\beta \\
\alpha\end{array}$ & $\begin{array}{l}.4215 \\
.4284\end{array}$ & .0857 & v.w. + & $\beta$ & & & $\begin{array}{l}.8195 \\
.8473\end{array}$ & & $\begin{array}{l}\text { v.v.w. } \\
\text { w. }\end{array}$ & $\begin{array}{l}x_{2} \\
x_{2}\end{array}$ \\
\hline & $\alpha$ & .4457 & & w. + & $\mathbf{x}_{2}$ & 310 & $\alpha$ & .8563 & .0856 & m. & $\beta$ \\
\hline
\end{tabular}

appearance of these extra reflections may indicate that the lattices of the $\beta$ - and $\beta^{\prime}$-phases are more complicated than those assigned to these phases by Ölander, but they may also belong to some other phases. However, the reflections do not fit either in a quadratic form of the $\alpha_{3}$-type, or in the tetragonal quadratic form proposed by Köster and Schneider. The $x_{2}$-phase is probably one of the $\gamma$ - or $\delta$-phases of Ölander.

For the $\beta$ - and $\beta^{\prime}$-phases the lattice parameters at different compositions were (room temperature):

The $\beta$-phase

$\begin{array}{ccc}\text { Atomic \% Cd } & a \text { in } \mathrm{kX} & V \text { in } \mathrm{kX}^{3} \\ 46,3 & 3.303 \pm .002 & 36.02 \\ 48,1 & 3.304 & 36.07 \\ 48,5 & 3.305 & 36.10 \\ 50,1 & 3.305 & 36.10 \\ 54,2 & 3.308 & 36.20\end{array}$


The $\beta^{\prime}$-phase

\begin{tabular}{|c|c|c|c|c|}
\hline Atomic \% Cd & $a$ in $\mathrm{kX}$ & $b$ in $k x$ & $c$ in $\mathbf{k X}$ & $V$ in $\mathbf{k X}^{3}$ \\
\hline 46.3 & $3.125 \pm .003$ & $4.868 \pm .004$ & $4.757 \pm .004$ & 72.36 \\
\hline 47.6 & 3.144 & 4.851 & 4.755 & 72.52 \\
\hline 48.1 & 3.158 & 4.845 & 4.758 & 72.80 \\
\hline
\end{tabular}

For the $\beta$-alloys Owen and Rees have given parameters that are considerably larger than ours and which decrease with increasing cadmium content. However, the cadmium atom is larger than the gold atom $\left(r_{C d}=1.47 \mathrm{kX}\right.$, $r_{A u}=1.40 \mathrm{kX}$ ) and thus an increase in the cell dimensions seems more probable. Besides, both the $\alpha$ and the $\alpha_{2}$ alloys show lattice dimensions which increase with increasing cadmium content. The $a$-axis of the $\beta^{\prime}$-alloys also increases with the cadmium content, but here the $b$-axis decreases and the $c$-axis is constant. The increase of the $a$-axis dominates and thus even in this case the cell volume increases with the cadmium content.

Some experiments by Owen and Rees show that the photographs of the $\beta$-alloys contain only the reflections of the body-centered cube, if the photographs are taken immediately after the quenching operation (that not all the reflections from the simple cube appeared, is probably due to the short exposure of only 30 minutes), but if the exposure was delayed for some time, the photographs contained a number of extra reflections. This fact makes it questionable whether our alloys - the powder photographs of which show unidentified reflections ( $x_{1}$ and $x_{2}$ in the table) - can be in spite of this looked upon as alloys in single phase regions. This seemed to be possible, as they showed variation of the cell dimensions with the composition. The dimensions of the $\beta^{\prime}$-phase in the alloys also containing $\alpha_{2}$-phase, together with this variation, were used in attempts to fix the boundary between the $\alpha_{2}+\beta$ region and the $\beta$ region. The position of the boundary was to be compared with Ölander's boundary, which runs from $44.7\left(300^{\circ} \mathrm{C}\right)$ to $41.2\left(550^{\circ} \mathrm{C}\right)$ atomic $\%$ Cd. It was calculated to be at $47.5\left(200^{\circ} \mathrm{C}\right), 44.8\left(400^{\circ} \mathrm{C}\right)$ and $44.8\left(550^{\circ} \mathrm{C}\right)$ atomic $\% \mathrm{Cd}$. It is, however, rather uncertain whether the dimensions of the phase in the two-phase alloys correspond to the quenching temperature. The mobility of the atoms is perhaps too great and Ölander's determination of this boundary is probably more reliable. Thus in the equilibrium diagram, (fig. 4) the boundaries of the $\beta$ - and $\beta^{\prime}$-phase have been taken from Ölander's measurements.

It is obvious that an investigation of the equilibrium diagram with quenched alloys cannot be considered as satisfactory in the $\beta$-region. Hence we made some X-ray photographs of wires in a high temperature camera (see p. 77) 
at temperatures from $20^{\circ} \mathrm{C}$ to $500^{\circ} \mathrm{C}$. It appeared that at temperatures higher than about $400^{\circ} \mathrm{C}$ the evaporation of cadmium from the wires was so rapid that changes from $\beta$ to $\alpha_{2}$ or $\alpha$ occured during the exposure. Thus we were not able to investigate the $\beta$-region from the solidus curve down to $400^{\circ} \mathrm{C}$.

The X-ray photographs of wires cast from $\beta$-alloys showed transformation to cubic $\beta$-phase at $85^{\circ} \pm 15^{\circ} \mathrm{C}$. Below the transition temperature, complicated patterns were obtained. The small radius and consequently low resolving power of the high-temperature camera made the identification of the reflections rather difficult, but it seems that they belong to the orthorhombic $\beta^{\prime}$-phase. In any case it is certain that they fit in the quadratic form of this phase. The crystallites in the wires were rather large and strongly orientated with the result that the reflections were very spotty and difficult to measure. To avoid the orientation effects we also made $\mathrm{X}$-ray photographs on specimens prepared by mixing heat-treated powder of the alloy with Canada balsam into a thick paste, which was coated on a fine glass fibre. The intensities and spacings of the reflections in a photograph of an alloy with 47.5 atomic \% $\mathrm{Cd}$ agreed very well with those of the orthorhombic $\beta^{\prime}$-phase previously measured.

Ölander found that wires of $\beta^{\prime}$-phase at room temperature have a very remarkable rubber-like elasticity which is most pronounced at 47.5 atomic \% $\mathrm{Cd}$, for which reason he estimates the $\boldsymbol{\beta}^{\prime}$-region at this temperature to extend only between 47 and 48 atomic $\% \mathrm{Cd}$ (private communication). This rubberlike elasticity, however, disappears when the wire is held in boiling water. It is thus characteristic for the $\beta^{\prime}$-structure.

A specimen of an alloy with 50 atomic \% Cd at room temperature gave (as was the case with the quenched alloy of this composition) reflections belonging to the cubic $\beta$-phase and the $x_{2}$-phase. At higher temperatures (about $70^{\circ} \mathrm{C}$ ) the reflections of $\mathrm{x}_{2}$ disappeared and those of $\beta$ remained. Thus this" specimen probably passes the two-phase boundary at $70^{\circ} \mathrm{C}$. If this is true it is possible to super-cool the $\beta$-phase when it after cooling is mixed with $\mathbf{x}_{2}$ but not in single phase alloys. Our future work on the cadmium-rich AuCd-alloys will perhaps throw light on this question also. It is, however, certain that the stable phases in the $\beta$-region are at low temperatures the orthorhombic $\beta^{\prime}$-phase and at higher temperatures the cubic $\beta$-phase.

Köster and Schneider's measurements of the variation of the modulus of elasticity with the temperature show a definite transition at $30-60^{\circ} \mathrm{C}$, in rather good agreement with our findings. Ölander, on the other hand, believed that the transition occurs at $267^{\circ} \mathrm{C}$. With the $\mathrm{X}$-ray method he, however, only showed that the alloy was cubic at $400-450^{\circ} \mathrm{C}$, and orthorhombic at room temperature. The transition point was calculated from the temperature coefficient of the cell $\mathrm{Cd} \mid$ electrolyte $\mid \mathrm{Cd}, \mathrm{Au}$ for $\beta+\gamma^{\prime}$ and $\beta^{\prime}+\gamma^{\prime}$ alloy elec- 
Fig. 3. The dilatation-temperature curve from room temperature to $100^{\circ} \mathrm{C}$.

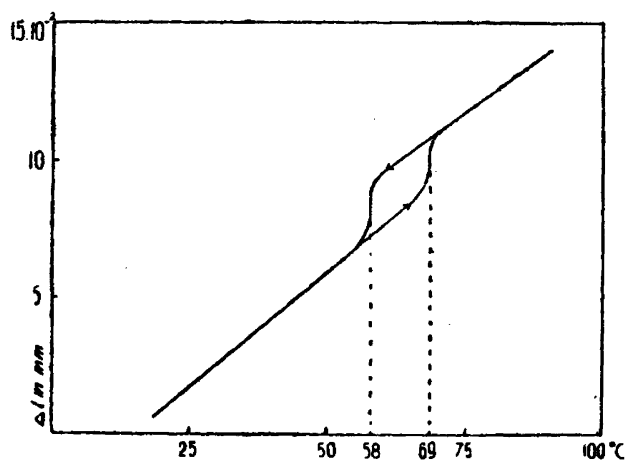

trodes. His measurements, however, were only extended down to $250^{\circ} \mathrm{C}$, and it seems that he had found some other transition.

We also determined the transition point dilatometrically. A rod which was $63.3 \mathrm{~mm}$ long and $5.7 \mathrm{~mm}$ in diameter was made from an alloy with $\mathbf{4 7 . 5}$ atomic \% $\mathrm{Cd}$. For the investigation we used a dilatometer constructed by Pyk, Stålhane, and Westberg. ${ }^{9}$ In fig. 3, one part of the dilatation-temperature curve is given. Slight super-heatings and super-coolings are difficult to avoid, even if the temperature is raised and lowered very slowly. However, the transition temperature could be estimated to be $64^{\circ} \pm 6^{\circ} \mathrm{C}$. There might also be a slight effect at about $290^{\circ} \mathrm{C}$ (fig. 4), i. e. not very far from Ölander's transition at $267^{\circ} \mathrm{C}$. Ölander's determination might be affected with rather large errors because of the small differences in temperature coefficient of the two forms $\beta$ and $\beta^{\prime}$. According to Köster and Schneider there is also an effect on the modulus of elasticity versus temperature curve at about this temperature: they obtained a maximum at $275^{\circ} \mathrm{C}$. However, the X-ray photographs show no structural change at this temperature.

In a recent paper, Kubaschewski ${ }^{10}$ concludes from calorimetric determinations of the heat content of an alloy of the composition AuCd just below

Fig. 4. The dilatation-temperature curve from $200^{\circ} \mathrm{C}$ to $325^{\circ} \mathrm{C}$.

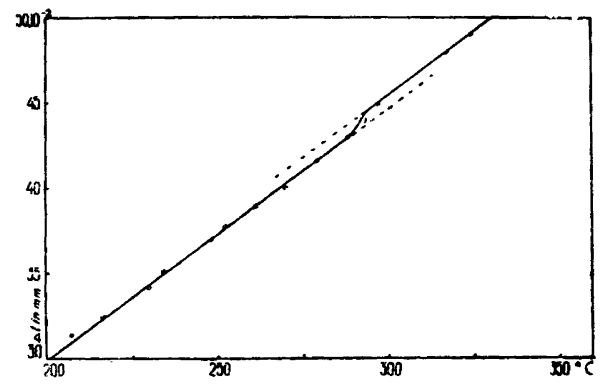




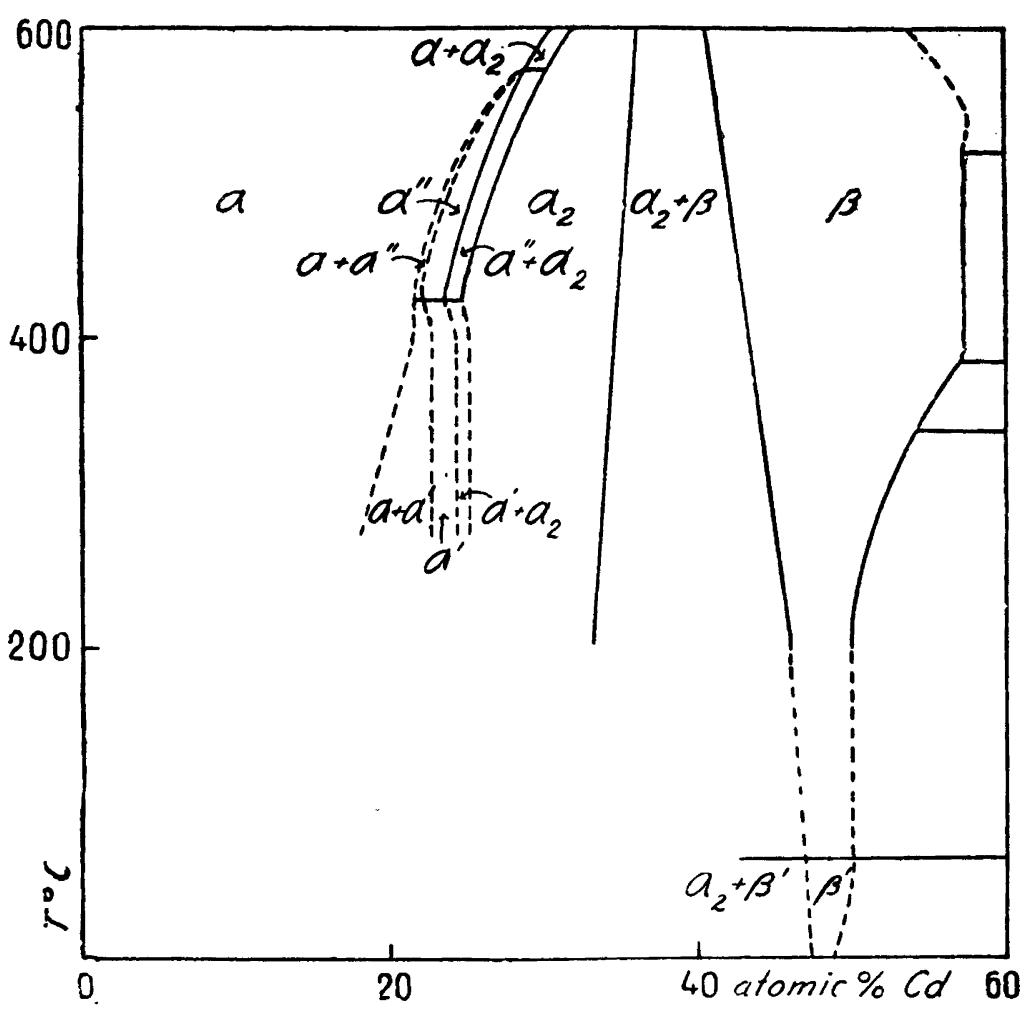

Fig. 5. Phase diagram of the gold-rich part of the gold-cadmium system.

and above the melting point that the $\beta$-phase becomes disordered before it melts. Owing to the rapid evaporation of $\mathrm{Cd}$ at elevated temperatures we have not been able to check this statement with $\mathrm{X}$-ray photographs. However, Ölander determined the degree of disorder to be $0.5 \%$ at $450^{\circ} \mathrm{C} .1,11$ As the melting point of the $\beta$-alloy at the composition AuCd is as high as $627^{\circ} \mathrm{C}$ it seems very reasonable that the alloy will be completely disordered before it melts.

\section{SUMMARY}

The results of the present studies, together with those of previous investigations, are shown in the equilibrium diagram in fig. 5. It differs from the recently published diagram of Owen and O'Donnell Roberts, and from that of Owen and Rees in the following respects: 
1. $\alpha^{\prime}$ denotes a tetragonally deformed ordered structure.

2. $\alpha^{\prime \prime}$ is a cubic structure, which is also ordered, the degree of order decreasing with increasing temperature. The $\alpha^{\prime \prime}$ and the $\alpha+\alpha^{\prime \prime}$ regions (if the latter exists) must both be very narrow. The cell dimensions of ordered and disordered alloys of the same composition were equal as far as we could make out by our measurements, and we could not fix the boundary between the two regions. Together they occupy about two atomic percentages and in the diagram the $\alpha+\alpha^{\prime \prime}$ region has been drawn very narrow without any experimental evidence.

3. $\alpha_{3}$ does not exist.

4. The $\beta$-phases have a transition at $64^{\circ} \mathrm{C} \pm 6^{\circ} \mathrm{C}$. The structure is changed from orthorhombic $\beta^{\prime}$ to cubic $\beta$ by this transition. Probably, another transition without any structural change occurs at $280-300^{\circ} \mathrm{C}$. The $\beta$-phase is ordered at low temperatures, but becomes disordered before it melts.

The $\alpha_{2}$-phase has a pure hexagonal close-packed structure only when the composition is near to $\mathrm{Au}_{2} \mathrm{Cd}$. In more gold-rich parts of the $\alpha_{2}$-region several reflections in the $\mathrm{X}$-ray photographs are broadened and weakened. This effect is probably due to the fact that there are occasional faults in the hexagonal close-packing.

We wish to thank Professor G. Hägg, who placed the high-temperature camera at our disposal, Mr. B. Stålhane, from whom we have borrowed the dilatometer, Professor A. Ölander for his encouraging interest in our work and Nobelstiftelsen for financial support.

\section{REFERENCES}

1. Ölander, A. J. Am. Chem. Soc. 54 (1932) 3819.

2. Köster, A., und Schneider, W. Z. Metallkunde 32 (1940) 156.

3. Owen, E. A., and O'Donnell Roberts, E. A. J. Inst. Met. 66 (1940) 389.

4. Owen, E. A., and Rees, W. H. J. Inst. Met. 67 (1941) 141.

5. Jette, E. R., and Foote, F. J. Chem. Phys. 3 (1935) 605.

6. Saldau, P. Intern. Z. Met. 7 (1914) 3; J. Russ. Phys.-Chem. Soc. 46 (1914) 994; 55 (1924) 275.

7. Edwards, O. S., and Lipson, H. Proc. Roy. Soc. (A) 180 (1942) 268.

8. Ölander, A. Z. Krist. (A) 83 (1932) 145.

9. Pyk, S., Stålhane, B., and Westberg, T. Jernkontorets Annaler (1935) no. 10.

10. Kubaschewski, O. Z. Phys. Chem. 192 (1943) 292.

11. Ölander, A. Z. phys. Chem. A, 165 (1933) 65. 